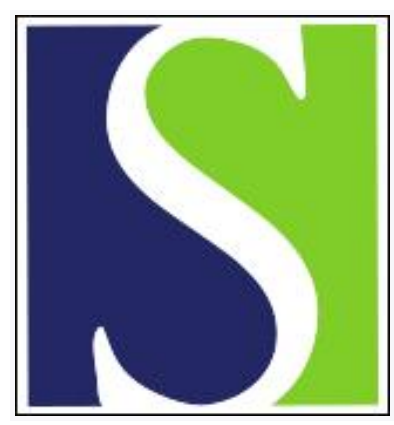

Scand J Work Environ Health 2011;37(1):1-5

https://doi.org/10.5271/sjweh.3078

Published online: 09 Aug 2010, Issue date: Jan 2011

Physical conditioning programs for improving work outcomes among workers with back pain

by Schaafsma F, Schonstein E, Ojajärvi A, Verbeek J

Affiliation: Faculty of Health Sciences, University of Sydney, Cumberland Campus, PO Box 170, Lidcombe (NSW) 1825 Australia.

f.g.schaafsma@gmail.com

The following articles refer to this text: 2012;38(3):282-290;

2012;38(2):134-143; 2013;39(1):57-65

Key terms: back disorder; back pain; exercise; physical conditioning program; return to work; review; sickness absence; sickness absence; work outcomes; worker health; worksite

This article in PubMed: www.ncbi.nlm.nih.gov/pubmed/20700550 


\section{Physical conditioning programs for improving work outcomes among workers with back pain}

by Frederieke Schaafsma, MD, PhD, ${ }^{1}$ Eva Schonstein, PhD, ${ }^{1}$ Anneli Ojajärvi, PhD, ${ }^{2}$ Jos Verbeek, MD, PhD ${ }^{2}$

Schaafsma F, Schonstein E, Ojajärvi A, Verbeek J. Physical conditioning programs for improving work outcomes among workers with back pain. Scand J Work Environ Health. 2011;37(1):1-5

Objectives The aim of this review was to assess the effect of physical conditioning programs, compared to no or alternative interventions, in reducing time lost from work among patients with back pain.

Methods We conducted a systematic review with meta-analysis and meta-regression of randomized controlled trials (RCT) of physical conditioning programs for workers with back-pain-related work disability.

Results We included 23 RCT with 3676 participants, with 13 studies having a low risk of bias. In 14 studies, physical conditioning programs were compared to "usual care". Among workers with acute back pain, there was no effect on sickness absence. For workers with subacute back pain, we found conflicting results. Among workers with chronic back pain, pooled results of five studies showed a small effect on sickness absence at one year follow-up [standardized mean difference (SMD) - $0.18,95 \%$ confidence interval (95\% CI) -0.37-0.00] but this effect disappeared at longer follow-up times. Six studies compared physical conditioning programs to exercise only with conflicting results. The addition of cognitive behavioral therapy to physical conditioning programs did not change the effectiveness. The meta-regression showed no significant effect of program intensity, inclusion of a workplace visit, occupation, setting of the intervention, the type of comparison, or the follow up time.

Conclusions The effectiveness of physical conditioning programs in reducing sick leave for workers with back pain remains uncertain. For acute back pain, these programs probably have no effect; for subacute back pain, the effect is unclear, and for chronic back pain there is a small effect at one year follow-up that does not last in the long run. Remaining heterogeneity could not be explained by meta-regression. A better understanding of the mechanism behind physical conditioning programs and return to work is needed to develop more effective interventions.

Key terms back disorder; exercise; return to work; review; sickness absence; worker health; worksite.

Back pain is a major medical and social problem that causes both individual physical and psychological distress and great expense to society in industrialized western countries (1). Most workers with back pain, their employers, and insurers agree that the goal of managing back pain is a timely return-to-work outcome following back-pain-related work disability.

Physical conditioning programs all incorporate some form of structured exercise or activity based on the idea that inactivity due to avoidance of painful activities can lead to so-called "deconditioning syndrome", which in turn can lead to more pain from attempts to move stiffened joints and muscles weakened by disuse. These programs have an explicitly stated expectation that as physical and functional capacities improve, so will the person's capability of returning to work. The programs include actual or simulated work tasks and can also address individual and work-related psychosocial factors that may play an important role in persisting symptoms and disability (2). This review was first published in 2003 (3) and was recently updated (4). New evidence was available since the previous search carried out in 2000 and the original search strategy was improved. The objective of this review is to assess the effect of physical conditioning programs on time lost from work among patients with back pain compared to no or alternative interventions.

1 Faculty of Health Sciences, University of Sydney, Lidcombe, New South Wales, Australia.

2 Tutka Team, Finnish Institute of Occupational Health, Kuopio, Finland.

Correspondence to: Dr F Schaafsma, Faculty of Health Sciences, University of Sydney, Cumberland Campus, PO Box 170, Lidcombe (NSW) 1825 Australia. [E-mail: f.g.schaafsma@gmail.com] 


\section{Methods}

We included (cluster) randomized trials of physical conditioning programs that evaluated the effect on time lost from work among adults with back-pain-related work disability. Physical conditioning programs were defined as exercises designed to restore an individual's function with the aim of improving work status by addressing capacity to cope with specific job demands. The programs could also include additional components. Work-status outcomes should be measured as either the time between intervention and return to work or work status at the end of follow-up.

We searched CENTRAL (The Cochrane Library 2008, issue 3), Medline, Embase, CINAHL, PsycINFO, and PEDro for the period May 2002 to June 2008. In addition, we searched the reference lists of identified studies and consulted domain experts. More information about the search strategy can be found in the original review (4). Two reviewers independently assessed study eligibility, extracted data, and assessed trial quality and clinical relevance. We used consensus to resolve disagreements. Risk of bias was analyzed for all included studies according to the recommendations of the Back Review Group (5). Quality of the evidence was assessed with the GRADE approach (5).

Interventions were considered homogeneous if they had similar back pain duration, follow-up time, and type of control group. Outcomes were plotted as standardized mean differences (SMD) or odds ratios (OR). We re-calculated OR into SMD according to the following formula recommended in the Cochrane Handbook: $\mathrm{SMD}=\ln (\mathrm{OR}) / 1.81$ (6).

We used Bayesian multivariable random-effects meta-regression (7) to explain remaining heterogeneity by intensity of the programs (intense or light), occupation (blue-collar, white-collar, or combined), inclusion of a workplace visit in the program, the continent where the study was executed, control intervention (care as usual, exercise, or psychological approach), and followup time. Both univariate meta-SMD and multivariate meta-SMD were calculated.

\section{Results}

We found 23 randomized controlled trials (RCT) with 28 comparisons that included 3676 participants (8-30). All interventions were related to work, contained exercises and had a focus on return to work. However, the number of sessions and the content varied greatly. We labeled the intensity of five interventions as "light" meaning that were delivered in fewer than five sessions (of one hour) or were described by the primary study author as a light intervention program $(13,15,18,25,30)$. Eighteen studies were labeled as "intense", meaning that they were delivered in more than five sessions or were delivered on a full-time basis for more than two weeks. Seventeen interventions were delivered by a multidisciplinary group (8-12, 14, 16-19, 21, 22, 24-26, 29, 30) and five were delivered by an individual physiotherapist $(13,15$, $20,27,28)$. In one study it was unclear who delivered the intervention (23). Fifteen interventions included an operant conditioning behavioral approach $(8-12,15,16$, 20-23, 25-27, 29). Fifteen interventions included occupational training or ergonomic advice $(9-11,14-17,19$, $21,22,24,25,28-30)$ and nine mentioned explicitly that return-to-work advice was included in the intervention $(15,16,18,20-22,26,27,29)$. Six interventions also included a workplace visit in their physical conditioning program $(16,18,20-22,29)$ and one intervention was executed at the workplace (26). Thirteen of the 23 studies were assessed as having a low risk of bias. Eight studies had flaws due to unclear or no allocation concealment $(8-10,14,17,20,23,24)$.

\section{Effects of physical conditioning programs}

For workers with acute back pain, none of the physical conditioning programs had an effect on sickness absence compared to usual care $(13,14,30)$. For workers with subacute back pain, we found conflicting results at six-month follow-up. One RCT (26) reported that the intense physical conditioning program was more effective than usual care [SMD $0.42,95 \%$ confidence interval $(95 \% \mathrm{CI})-0.76--0.08]$, but two other RCT $(15,27)$ showed no significant difference (pooled SMD $0.13,95 \%$ CI $-0.09-0.35)$. The same problem occurred at one year follow-up. One study (27) reported that the physical conditioning program was less effective than usual care (SMD $0.39,95 \%$ CI $0.02-0.77$ ), but three other RCT $(20,21,26)$ showed that their interventions were significantly more effective than usual care [pooled SMD $-0.42,95 \%$ CI $-0.65--0.18)$. The studies with a significant positive effect all involved the workplace.

For workers with chronic back pain, five RCT with 1093 workers $(9,12,16,23,25)$ showed that intense physical conditioning programs are more effective than usual care at one year follow-up (SMD - $0.18,95 \%$ CI $-0.37-0.00$ ) (figure 1). However, at 2-3-year follow-up, no difference in effect was measured anymore (pooled SMD -0.24, 95\% CI -0.58-0.10) (11, 18, 27).

For workers with chronic back pain, five studies (10, $11,17,22,24)$ compared intense physical conditioning programs with an exercise-only program. After 3 and 6 months follow-up, no difference in effect was measured $(17,22,24)$. After a one year follow-up, two RCT reported opposite effects $(10,11)$. 


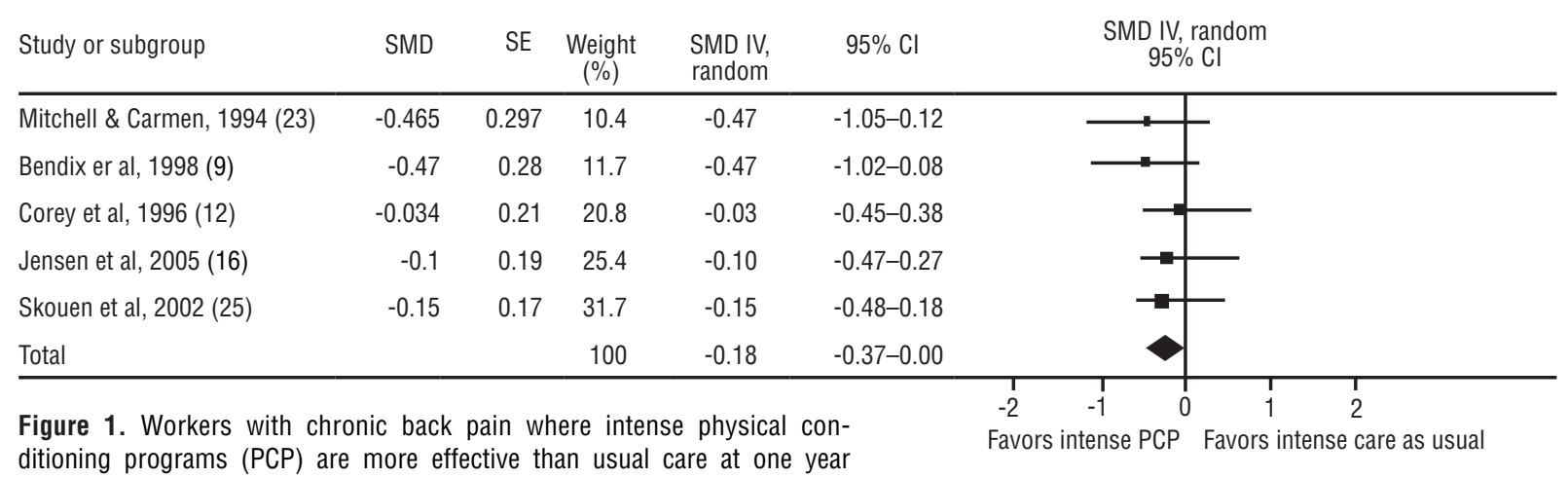
ditioning programs (PCP) are more effective than usual care at one year follow-up. (i) Test for heterogenity: $\mathrm{Tau}^{2}=0.00 ; \mathrm{Chi}^{2}=2.68, \mathrm{df}=4 \quad(\mathrm{P}=0.61)$; $\mathrm{I}^{2}=0 \%$. (ii) Test for overall effect: $\mathrm{Z}=1.91 \quad(\mathrm{P}=0.06)$. [SMD=standardized mean difference; $\mathrm{SE}=$ standard error; $95 \% \mathrm{Cl}=95 \%$ confidence interval.]

For workers with chronic back pain, physical conditioning programs with cognitive behavioral therapy (CBT) did not have more effect than programs without CBT $(8,16,29)$. Moreover, two other studies found that physical conditioning was more effective than CBT alone $(10,16)$.

\section{Meta-regression}

Table 1 shows the results of the meta-regression for the 28 comparisons. We could not identify any factor that explained the variation in outcomes between studies. Only interventions performed in Western Europe showed a non-significant trend towards a better result compared to those executed in the Nordic countries or North America.

\section{Discussion}

Intense physical conditioning programs were more effective in decreasing time off work among patients with chronic back pain when compared to care as usual; this was the case possibly also for patients with subacute pain but not for patients with acute pain. The effect probably does not last at the long-term follow-up of $2-3$ years. We found no added value of CBT in addition to a physical conditioning program. No factors could be identified that explained the variation in outcomes between studies.

For the systematic review and the meta-analysis, we followed the guidelines of the Back Review Group and the Cochrane Collaboration and pooled as much data as possible to increase potential effect sizes $(5,6)$. Based on expert judgment, we categorized studies beforehand in subgroups to minimize issues with heterogeneity. However, we still encountered high statistical heterogeneity in studies that clinically seemed homogeneous. This finding
Table 1. Results of univariate and multivariate Bayesian random effects meta-regression models ( $\mathrm{N}=28,23$ studies). [PCP=physical conditioning program; SMD=standardized mean difference; $95 \%$ $\mathrm{Cl}=95 \%$ confidence interval. $]$

\begin{tabular}{|c|c|c|c|c|c|}
\hline \multirow[t]{2}{*}{ Factor } & \multirow{2}{*}{$\begin{array}{c}\text { Number } \\
\text { of } \\
\text { studies }\end{array}$} & \multicolumn{2}{|c|}{$\begin{array}{l}\text { Crude meta- } \\
\text { regression model }\end{array}$} & \multicolumn{2}{|c|}{$\begin{array}{l}\text { Adjusted meta- } \\
\text { regression model }\end{array}$} \\
\hline & & $S M D^{a}$ & $95 \% \mathrm{Cl}$ & $S M D^{b}$ & $95 \% \mathrm{Cl}$ \\
\hline \multicolumn{6}{|l|}{ Intensity } \\
\hline Intense & 23 & $1^{c}$ & & $1^{\mathrm{c}}$ & \\
\hline $\begin{array}{l}\text { Light } \\
\text { Constant }\end{array}$ & 5 & $\begin{array}{r}-0.002 \\
-0.23\end{array}$ & $\begin{array}{r}-0.32-0.32 \\
-0.38--0.09\end{array}$ & -0.22 & $-0.72-0.29$ \\
\hline \multicolumn{6}{|l|}{ Workplace visit } \\
\hline No & 19 & $1^{c}$ & & $1^{c}$ & \\
\hline Yes & 9 & -0.03 & $-0.29-0.26$ & -0.06 & $-0.43-0.35$ \\
\hline Constant & & -0.22 & $-0.39--0.08$ & & \\
\hline \multicolumn{6}{|l|}{ Type of work } \\
\hline Variety & 22 & $1^{c}$ & & $1^{c}$ & \\
\hline Blue-collar & 5 & -0.11 & $-0.41-0.22$ & -0.07 & $-0.47-0.37$ \\
\hline White-collar & 1 & -0.15 & $-0.76-0.49$ & 0.16 & $-0.73-1.07$ \\
\hline Constant & & -0.20 & $-0.36--0.06$ & & \\
\hline \multicolumn{6}{|l|}{ Country } \\
\hline Nordic countries & 12 & $1^{\mathrm{c}}$ & & $1^{c}$ & \\
\hline Western Europe & 11 & 0.23 & $-0.01-0.52$ & 0.26 & $-0.14-0.67$ \\
\hline North America & 5 & 0.03 & $-0.34-0.40$ & -0.13 & $-0.63-0.37$ \\
\hline Constant & & -0.33 & $-0.53--0.16$ & & \\
\hline \multicolumn{6}{|l|}{ Comparison } \\
\hline Care as usual & 16 & $1^{c}$ & & $1^{\mathrm{c}}$ & \\
\hline Exercise & 5 & -0.06 & $-0.40-0.29$ & -0.24 & $-0.71-0.25$ \\
\hline $\begin{array}{l}\text { Psychological } \\
\text { approach }\end{array}$ & 4 & -0.28 & $-0.67-0.09$ & -0.39 & $-0.94-0.10$ \\
\hline $\begin{array}{l}\text { PCP + psycho- } \\
\text { logical approach }\end{array}$ & 3 & 0.43 & $-0.02-0.93$ & 0.49 & $-0.07-111$ \\
\hline Constant & o & -0.22 & $-0.39--0.07$ & 0.40 & I. \\
\hline \multicolumn{6}{|l|}{ Follow-up time } \\
\hline Long & 20 & $1^{c}$ & & $1^{c}$ & \\
\hline Intermediate & 5 & 0.25 & $-0.06-0.60$ & 0.09 & $-0.35-0.59$ \\
\hline Short & 3 & 0.14 & $-0.33-0.61$ & 0.22 & $-0.37-0.84$ \\
\hline Constant & & -0.29 & $-0.45--0.15$ & & \\
\hline
\end{tabular}

Constant $-0.24-0.64-0.10$

a Univariate.

${ }^{b}$ Multivariate, adjusted for all the other variables in the model.

c Reference. 
is not unique and needs further investigation (31). The meta-regression made it possible to analyze which variable can explain the differences in effect on work status when all the studies are included. Two previous publications have also combined these two analysis methods $(32,33)$. One review looked at specific components of exercise interventions, such as program design, delivery type, intensity, and additional treatment (32). Another review analyzed factors (such as study design, pain duration, involvement of workers' compensation, and previous surgery) in various types of interventions for back pain (33). In contrast to these two publications, none of the factors we included in the meta-regression could explain why some studies are effective and others are not.

It remains unclear if physical conditioning programs reduce sickness absence more than exercise therapy for workers with chronic back pain. The difference between physical conditioning and exercise lies in the explicit objective of enabling the individual to return to work in the conditioning programs. Since both types of interventions can be effective, the added value of the focus on work in physical conditioning programs remains unclear (32). Most studies compared physical conditioning programs with care as usual. However, it was not always clear what care as usual was. A cost-effectiveness analysis should show if alternative interventions use fewer resources and thus are less costly but equally effective.

Results of this updated Cochrane review and metaregression show that more research is needed to understand why some physical conditioning programs are effective and others are not.

\section{Concluding remarks}

The effectiveness of physical conditioning programs in reducing sick leave for workers with back pain remains uncertain. Remaining heterogeneity could not be explained by meta-regression. A better understanding of the mechanism behind physical conditioning programs and return to work is needed to develop more effective interventions.

\section{Acknowledgements}

This paper is based on a Cochrane Review published in Cochrane Database of Systematic Reviews 2010, Issue 1. Art No: CD001822. DOI: 10.1002/14651858.CD001822. pub2. Cochrane Reviews are regularly updated as new evidence emerges and in response to feedback, and the Cochrane Library should be consulted for the most recent version of the review. We thank Dianna Kenny, Eirik Ulvestad, and Karyn Whelan for their contribution to the Cochrane Review on which this paper is based.

\section{References}

1. Hlobil H, Staal JB, Twisk J, Köke A, Ariëns G, Smid T, et al. The effects of a graded activity intervention for low back pain in occupational health on sick leave, functional status and pain: 12-month results of a randomized controlled trial. J Occup Rehabil. 2005;15(4):569-80.

2. Waddell G, Burton K. Evidence review: occupational health guidelines for the management of low back pain at work principal recommendations. London: Faculty of Occupational Medicine; 2000.

3. Schonstein E, Kenny DT, Keating JL, Koes BW. Work conditioning, work hardening and functional restoration for workers with back and neck pain. Cochrane Database Syst Rev. 2003;(1):CD001822.

4. Schaafsma F, Schonstein E, Whelan KM, Ulvestad E, Kenny DT, Verbeek JH. Physical conditioning programs for improving work outcomes in workers with back pain. Cochrane Database Syst Rev. 2010;(1):CD001822.

5. Furlan AD, Pennick V, Bombardier C, van Tulder M, Editorial Board, Cochrane Back Review Group. 2009 updated method guidelines for systematic reviews in the Cochrane Back Review Group. Spine (Phila PA 1976). 2009;34(18):1929-41.

6. Higgins JPT, Green S. Cochrane Handbook of Systematic Reviews. West Sussex (United Kingdom): The Cochrane Collaboration; 2008.

7. Spiegelhalter D, Abrams KR, Myles JP. Bayesian approaches to clinical trials and health-care evaluation. Chichester (United Kingdom): John Wiley \& Sons, Ltd; 2004.

8. Altmaier EM, Lehmann TR, Russell DW, Weinstein JN, Kao $\mathrm{CH}$. The effectiveness of psychological interventions for the rehabilitation of low back pain: a randomised controlled trial evaluation. Pain. 1992;49:329-35.

9. Bendix AF, Bendix T, Hæstrup C, Busch E. A prospective, randomized 5-year follow-up study of functional restoration in chronic low back pain patients. Eur Spine J. 1998;7:111-9.

10. Bendix A, Bendix T, Labriola M, Bøkgaard P. Functional restoration for chronic low back pain/ two-year follow-up of two randomized clinical trials. Spine. 1998;23(6):717-25.

11. Bendix T, Bendix A, Labriola M, Hæstrup C, Ebbehøj N. Functional restoration versus outpatient physical training in chronic low back pain. Spine. 2000;25(19):2494-500.

12. Corey DT, Koepfler LE, Etlin D, Day HI. A limited functional restoration program for injured workers: a randomised trial. J Occup Rehabil. 1996;6(4):239-49.

13. Faas A, van Eijk J Th M, Chavannes AW, Gubbels JW. A randomised trial of exercise therapy in patients with acute low back pain: efficacy on sickness absence. Spine. 1995;20(8):941-7.

14. Gatchel RJ, Polatin PB, Noe C, Gardea M, Pulliam C, Thompson J. Treatment- and cost-effectiveness of early intervention for acute low-back pain patients: a one-year prospective study. J Occup Rehabil. 2003;13(1):1-9. 
15. Heymans MW, de Vet HCW, Bonger PM, Knol DL, Koes BW, van Mechelen W. The effectiveness of high-intensity versus low-intensity back schools in an occupational setting. Spine. 2006;31(10):1075-82.

16. Jensen IB, Bergström G, Ljungquist T, Bodin L. A 3-year follow-up of a multidisciplinary rehabilitation programme for back and neck pain. Pain. 2005;115:273-83.

17. Jousset N, Fanello S, Bontoux L, Dubus V, Billabert C, Vielle $\mathrm{B}$, et al. Effects of funtcional restoration versus 3 hours per week physcial therapy: a randomized controlled study. Spine (Phila PA 1976). 2004;29(5):487-94.

18. Karjalainen K, Malmivaara A, Mutanen P, Roine R, Hurri H, Pohjolainen T. Mini-intervention for subacute low back pain. Spine. 2004;29(10):1069-76.

19. Kool J, Bachmann S, Oesch P, Knuesel O, Ambergen T, de Bie $\mathrm{R}$, et al. Function-centered rehabilitation increases work days in patients with nonacute nonspecific low back pain: 1-year results from a randomized controlled trial. Arch Phys Med Rehabil. 2007;88:1089-94.

20. Lindström I, Ohlund C, Eek C, Wallin L, Peterson L-E, Nachemson A. Mobility, strength, and fitness after a graded activity program for patients with subacute low back pain. a randomised prospective clinical study with a behavioural approach. Spine (Phila Pa). 1992;17(6):641-52.

21. Loisel P, Abenhaim L, Durand P, Esdaile JM, Suissa S, Gosselin L, et al. A population based, randomised clinical trial on back pain management. Spine. 1997;22(24):2911-8.

22. Meyer K, Fransen J, Huwiler H, Uebelhart D, Klipstein A. Feasibility and results of a randomised pilot-study of a work rehabilitation programme. J Back Musculoskelet Rehabil. 2005;18:67-78.

23. Mitchell RI, Carmen GM. The functional restoration approach to the treatment of chronic pain in patients with soft tissue and back injuries. Spine (Phila Pa). 1994;19(6):633-42.

24. Roche G, Ponthieux A, Parot-Shinkel E, Jousset N, Bontoux L, Dubus V, et al. Comparison of a functional restoration program with active individual physical therapy for patients with chronic low back pain: a randomized controlled trial. Arch Phys Med Rehabil. 2007;88:1229-35.
25. Skouen JS, Grasdal AL, Haldorsen EMH, Ursin H. Relative cost-effectiveness of extensive and light multidisciplinary treatment programs versus treatment as usual for patients with chronic low back pain on long-term sick leave. Spine (Phila Pa). 2002;27(9):901-10.

26. Staal JB, Hlobil H, Twisk JWR, Smid T, Köke AJA, van Mechelen W. Graded activity for low back pain in occupational health care. Ann Intern Med. 2004;140:142-3.

27. Steenstra IA, Anema JR, Bongers PM, de Vet HCW, Knol DL, van Mechelen W. The effectiveness of graded activity for low back pain in occupational health care. Occup Environ Med. 2006;63:718-25.

28. Storheim K, Brox JI, Holm I, Koller AK, Bø K. Intensive group training versus cognitive intervention in sub-acute low back pain: short-term results of a single-blind randomized controlled trial. J Rehabil Med. 2003;35:132-40.

29. van den Hout JHC, Vlaeyen JWS, Heuts PHTG, Zijlema JHL, WIjnen JAG. Secondary prevention of work-related disability in nonspecific low back pain: does problem-solving therapy help?: a randomized clinical trial. Clin J Pain. 2003;19(2):87-96.

30. Wright A, Lloyd-Davies A, Williams S, Ellis R, Strike P. Individual active treatment combined with group exercise for acute and subacute low back pain. Spine. 2005;30(11):1235-41.

31. Furukawa TA, Streiner DL, Hori S. Discrepancies among megatrials. J Clin Epidemiol. 2000;53:1193-9.

32. Hayden JA, van Tulder MW, Tomlinson G. Systematic review: strategies for using exercise therapy to improve outcomes in chronic back pain. Ann Intern Med. 2005;142:776-85

33. Furlan AD, Tomlinson G, Jadad AR, Phil D, Bombardier C. Examining heterogeneity in meta-analysis/ comparing results of interventions for low back pain. Spine (Phila Pa) 2008:33(3):339-48.

Received for publication: 7 June 2010 